\section{Kekerabatan secara Ekolinguistik Bahasa Bima di NTB dan Bahasa Sabu di NTT}

I Gede Budasi

FBS Universitas Pendidikan Ganesha Singaraja Surel: yaysurya8@yahoo.com

\title{
INTISARI
}

Bahasa Bima di NTB dan Sabu di NTT dihipotesis diturunkan dari Protobahasa Autronesia Tengah bagian Tengah (Central Malayo Polynesia). Dua bahasa ini merupakan dua bahasa yang berbeda berdasarkan analisis kuantitatif sesuai hasil studi terdahulu (Budasi, 2014). Dalam studi tersebut kedua bahasa itu telah ditetapkan kedekatan kekerabatannya pada angka $26 \%$ dan keduanya tidak tergolong dalam satu subkelompok bahasa di daerah tersebut. Dalam studi ini, beberapa kosakatanya ditemukan memiliki kesamaan dan kemiripan fonetik. Kemiripan bentuk itu dapat dijumpai pada 56 pasangan kognat dari dua bahasa itu melalui penelusuran 200 kosakata pada Daftar Kosakata Swadesh. Pantulan etimon Proto Austronesia (PAn) pada kedua bahasa itu ada yang berbentuk tetap (retensi) atau mengalami perubahan fonem, penghilangan, penambahan fonem, atau keduanya, atau substitusi fonem. Selanjutnya, dari 56 kognat itu ditemukan 28 leksikon di antaranya berkaitan erat dengan lingkungan hidup pada Suku Bima di NTB dan Suku Sabu di NTT. Kosakata kognat itu meliputi: kosakata yang bermakna cacing, kutu, dan telur (yang tergolong binatang dan satwa); kayu, daun, akar, bunga, dan buah (yang tergolong tumbuhan dan tanaman); jarum, tali, abu, api, air, minyak, kabut, bulan, asap, batu, pasir, dan air (tergolong benda dan lingkungan alam); tipis, baru, takut, mati, hidup, tajam busuk, dan panas (tergolong kategori sifat dan keadaan). Dengan demikian, kekerabatan kedua bahasa itu tidak hanya nampak pada kekerabatan dekat secara kuantitatif dan kualitatif saja, namun juga memiliki kedekatan kekerabatan dekat secara ekolinguistik disamping adanya kekerabatan yang disebabkan oleh peristiwa politis dan kawin-mawin pada masa-masa kerajaan Sabu-Bima-Makasar di jaman dulu.

Kata kunci: protobahasa, kognat, ekolinguistik

\section{PENDAHULUAN}

Bahasa-bahasa Bima (NTB) dan Sabu di NTT diturunkan dari bahasa proto yang sama, yaitu Protobahasa Autronesia Tengah bagian Tengah (Central Malayo Polynesia) (Fernandez, 2007; Mbete, 1990; Halus, 2010; Ino, 2013). Penutur kedua bahasa ini diyakini pernah berhubungan dimasa lampau. Secara kuantitatif kedua bahasa Bima dan Sabu dalam studi Budasi (2007 dan 2014) kedua bahasa itu ditemukan berada pada tingkat kekerabatan terdekat dibandingkan dengan bahasa-bahasa daerah lainnya di NTT-NTB (Budasi, 2014). Salah satu penyebab munculnya perbedaan kosa kata kedua bahasa itu diyakini karena adanya persebaran manusia di wilayah NTT-NTB yang telah mengubah peradaban penutur bahasa protonya mengingat manusia dan bahasa tidak dapat dipisahkan karena bahasa melekat pada diri manusia. Bahasa dan budaya manusia pada umumnya akan selalu dibawa kemanapum mereka bepergian. Lingkungan baru akan berpengaruh pula akan cepat lambatnya perubahan bahasa yang mereka 
bawa. Misalnya, seperti sudah adanya penutur bahasa lainnya di daerah baru. Akulturasi budaya dan bahasa dari kedua kelompok penutur kedua bahasa yang berbeda itu tidak terhindari dan bahasa dari penutur bahasa yang ada itu akan mengubah bahasa dan budaya mereka.

Dalam kontek ini, Rijal (2015) berpendapat jika terdapat etnis yang baru membawa bahasa lain berinteraki intensif dengan penutur bahasa dari dua etnis yang berbaur itu sangat memungkinkan bahasa dan budaya merekapun akan mengalami pembauran di lingkungan tempat mereka bertemu. Etnis yang ditinggalkan akan menganggap dirinya sebagai etnis yang asli. Terkait dengan ini, Fernandez (2007) berpandangan bahwa bila dua bahasa atau lebih yang letak geografis pentuturnya pada tempat atau pulau yang berbeda, maka bahasa induknya atau bahasa protonya secara genetis dapat ditelusuri. Dengan demikian jejak perkembangan bahasabahasa daerah seperti yang tersebar di suatu wilayah seperti NTT dan NTB sangat mungkin bisa ditelusuri. Berdasarkan hasil penelitian terdahulu, bahasa-bahasa di Sumba lebih dekat kekerabatannya dengan Bahasa Sabu dibandikan dengan dengan Bahasa Bima. Penelitian Budasi (2014) menunjukan bahwa Bahasa Sabu lebih dekat kekerabatannya dengan bahasa Sumba dan bahasa Bima dibandinggkan dengan bahasa daerah lainnya. Oleh karena itu, menarik untuk diteliti lebih jauh adalah hal-hal yang dapat merekatkan hubungan penutur Suku Bima di NTB dengan Suku Sabu di NTT, utamanya dalam aspek ekolinguistik. Secara umum setiap turunan bahasa diasumsikan sebagai suatu bahasa yang memiliki bunyi yang mirip dan berbeda (Alwi, dkk 2003; Rijal 2015). Selanjutnya, artikel ini mendeskripsiskan tentang data kebahasaan secara kualitatif sebagai evidensi kekerabatan Bahasa Bima di NTB dengan Bahasa Sabu di Pulau Sawu dan medeskipsikan pula perbandingannya secara ekolinguistik.

Pendeskripsian tersebut dilandasi dari suatu asumsi bahwa kemiripan dan kesamaan ciri-ciri fonetis pada sejumlah kata-kata kognat dalam dua bahasa atau lebih yang berbeda, namun berkeluaga dekat sangat erat kaitannya dengan kesamaan budaya penuturnya. Bila ditemukan kosakata pada dua bahasa yang berbeda berarti penutur kedua bahasa itu dalam waktu dan periode tertentu dimasa lampau hidup pada lingkungan yang sama dan pada bahasa serta budaya yang sama. Untuk mengungkap fakta ilmiah guna memahami keterkaitan lingkungan dengan bahasa yang digunakan oleh masyarakat tutur tertentu, seorang peneliti hendaknya dapat mengkolaborasikan dua disiplin ilmu yang saling kait mengkait. Dalam hal ini yang dimaksud adalah ekolinguistik, yaitu dua disiplin ilmu yang berbeda: ekologi dan linguistik (Subiyanto, 2015). Ekologi mempelajari hubungan timbal balik antara mahluk hidup dan lingkungannya. Sedangkan linguistik membahas bahasa dan berbagai aspeknya secara ilmiah (Alwi dkk, 2003). Dengan demikian, Muhlhauser (2001) berpandangan bahwa penelitian ekolinguisik dapat menjangkau lintas bidang. Dalam arti bilogisnya, peneliti bahasa dengan 
pendekatan lingusitik bisa berkolaborasi dengan berbagai lintas bidang seperti geograpi fisik, bilogi.

Dalam perspektif ekolinguistik, bahasa dan komunitas penuturnya dipandang sebagai organisme yang hidup secara bersistem dalam suatu kehidupan sosial budaya masyarakatnya. Bahasa dalam kontek ini merekam kondisi lingkungan ragawi dan sosial. Apabila perhatian penutur suatu bahasa terhadap lingkungan sekitarnya rendah maka kondisi tersebut merupakan suatu penyebab suatu ekosistem itu bertambah kritis dan pada akhirnya leksikon pada ekosistem itu akan menjadi punah. Menurut Al Gayoni (2010:1) jika keragaman hayati banyak yang hilang maka pelbagai kerusakan dapat terjadi baik secara fisik, biologis, dan sosiologis terhadap kebertahanan lingkungan. Jika demikian halnya maka akan terjadi ketidak seimbangan ekosistem yang menyulut akan adana kepunahan bahasa. Dengan demikian, maka ekolinguistik merupakan sebuah disiplin ilmu yang dapat dimanfaakan untuk mengkaji lingkungan dalam perspektif linguistik karena perubahan sosioekologis dapat mempengaruhi penggunaan bahasa serta perubahan nilai budayanya dalam sebuah masyarakat. Selanjutnya, dua bahasa berkerabat atau lebih akan dapat ditelusuri kadar kebertahanan leksikonnya bilamana ditelusuri secara sistematis dan dapat pula ditelusuri keterhubungan kekeluargaan bahasanya. Sehubungan dengan hal itu, menurut Fernandez (2007) linguistik historis komparatif dapat menawarkan suatu pendekatan dan teknik untuk menelusuri keterhubungan perkembangan serta pembauran dua bahasa berkerabat atau lebih dalam suatu lingkungan tertentu pada masa tertentu. Studi yang demikian mengkombinasikan dua atau lebih disiplin ilmu untuk mendeskripsikan evidensi-evidensi kebahasaan secara ilmiah akan dapat saling melengkapi dalam rangka menemukan penjelasan tentang suatu kebenaran ilmiah.

Penelitian deskriptif kualitatif ini memaparkan kekerabatan Bahasa Bima dan Sabu secara ekolinguistik dengan menerapkan metode komparatif sesuai pandangan Bloomfield (1933) dalam Fernandez (2007), yaitu dengan membandingan 200 glos kedua bahasa yang terdapat dalam 200 Kosakata Swadesh. Glos yang terisi diperbandingkan berdasarkan kedekatan korespondensi bunyi dengan mempertimbangkan distribusi bunyi secara lingkungan artikulasi. Penelitian ini melibatkan 3 informan yang ditentukan berdasarkan kriteria Samarin (1981 dalam Fernandez 2007). Ketigayang dimaksud adalah 3 oang masisng masing penutur kedua bahasayang diteliti. Keterhubungan kedua bahasa itu ditelusuri ciri-ciri kesamaan fitur-fitur linguistiknya. Pada tahap analisis, transkripsi fonetis ditranskripsikan dalam bentuk abjad latin sesui dengan glos yang dilafalkan oleh para informan. Tanskripsi leksikon diperkuat dengan penulisan bunyi-bunyi bahasa melalui penggunaan huruf atau istlilah fonetik (Chaer, 2007) Selanjutnya, bentuk leksikon dalam glos yang erat dengan lingkungan hidup dideskripsikan sebagai bukti kekerabatan kedua bahasa itu secara ekolinguistik. 
Terkait dengan studi kebahasaan di daerah Bima NTB dan di Sabu NTT, ternyata sudah ada beberapa ahli yang memfokuskan perhatian pada penelitian yang bersifat sinkronis pada kedua bahasa yang berkerabat baik di wilayah Bima NTB maupun Sabu di NTT. Studi Erwin, Wayan, \& Arifin (2013), misalnya menunjukkan adanya perbedaan variasi bahasa antara penutur bahasa Bima yang berumur tua dan muda. Yang penutur berumur tua cendrung menggunakan bahasa standar dan bahasa halus, sedangkan yang muda juga menggunakan bahasa standar namun juga sangat sering menggunakan bahasa yang kurang sopan. Studi ini juga menemukan perbedaan variasi bahasa antara bahasa laki-laki dengan bahasa perempuan. Penutur yang berumur sama ditemukan menggunakan bahasa Bima standar. Masih terkait dengan studi kebahasaan, studi Yani (2013) menunjukan bahwa penutur bahasa Bima yang bekerja di Otoritas Pelabuhan Utama Tanjung Perak Surabaya menunjukkan bahwa cara pengucapan bahasanya terdapat perbedaan dengan penutur bahasa Bima yang berdomisili si Surabaya. Pilihan bahasa yang mereka gunakan sehari-hari di Surabaya akan sangat tergantung pada situasi dimana dengan etnis bahasa apa mereka bicara. Mereka cukup gampang menyesuaikan diri dalam berkomunikasi dengan berbagai etnis yang ada di Surabaya.

Studi dialektologi dilakukan oleh Yusra, Lestari, \& Ahmad (2016) tentang linguistik analisis antara bahasa Bima dengan Isolek Sambori dengan memanfaatkan teknik leksikostatistik. Studi ini menyimpulkan bahwa Isolek Sambori merupakan dialek dari bahasa Bima. Studi Historis Linguistik Komparatif yang telah pernah dilakukan Budasi, Indriyani \& Sudirman (2018) tidak menjangkau Isolek Sambori, namun menjangkau isolek Toloweri, Mbojo, Sanggar, Bima, dan Kolo. Ternyata di antaranya hanya Bima, Kolo, dan Sanggar saja yang berstatus bahasa sesuai klasifikasi bahasa yang sudah ditentukan. Yang lainnya berstatus sebagai dialek bahasa Bima. Jika Sambori dalam studi Yusra, Lestari, \& Ahmad (2016) menemukan Sambori adalah dialek Bima, maka dapat dikatakan bahwa sejauh ini Bima memiliki 3 dialek, yaitu dialek Toloweri, Mbojo, dan Sambori..

Beberapa studi kebahasaan yang dilakukan di Sabu adalah seperti yang dilakukan oleh Bire (2013) tentang kata majemuk bahasa Sabu. Studi tersebut menunjukkan bahwa dalam bahasa Sabu ditemukan 6 jenis kata majemuk dalam susunan (1) kata majemuk Nomina dan Nomina, (2) Nomina dan Verba, (3) Verba dan Nomina, (4) Verba Verba, (5) Nomina dan Adjectiva, dan (6) Adjectiva Nomina. Studi lainnya adalah yang dilakukan oleh Isu (2014) tentang sistem fonem bahasa Sabu. Dalam studi ini bahasa Sabu ditemukan memilki segmen vowel yang meliputi: li/, /u/, /e/, / / /, /o/, dan /a/. Sementara, untuk segmen konsonannya ditemukan berupa : /p, /b/, /t/, /d/, / k/, /g/, lj/, /h/, /m/, /n/, /r/, /l/, /ng/, /w/, /bh/, /dh/,/ dj/, /g/h, dan /ny/.

Terkait dengan non bahasa, satu-satunya ahli yang membahas keterkaitan Sabu dengan Bima adalah Kapita (1976a) dan (1976b). Kapita telah menulis tentang "Sumba dalam Jangkauan 
Jaman" dan"Masyarakat Sumba dan Adat Istiadatnya" Dari kedua tulisan Kapita tersebut, terdapat uraian tentang hubungan kesejarahan terutama dari sisi politis antara kaitan suku Sabu dan suku Bima di jaman dahulu yang menyatakan bahwa Sabu berada dibawah kendali kerajaan Bima dan disebutkan setiap perdagangan antar kerajaan dari Sabu ke Makasar melewati pelabuhan laut besar di Bima. Dengan demikian, pedagang-pedagang dari Sabu yang menggunakan kapal laut melewati Bima maka mereka diwajibkan membayar pajak. Karena jarak yang begitu jauh antara Sabu dan Makasar maka tidak sedikt orang-orang Sabu singgah dan berhenti melakukan perjalanan ke Makasar dan memutuskan pemberhentian atau persinggahan etnis sabu di Bima. Hal ini menggiring situasi terjadinya kawin-mawin antara etnis Sabu dan etnis Bima.

Berdasarkan uraian tentang adanya studi kebahasaan di Bima dan Sabu begitupula terjadinya peristiwa peristiwa kawin-mawin yang diuraikan diataas, maka dapat dipastikan bahwa belum ada ahli yang meneliti tentang kekerabatan ekolinguistik khusus mengenai perbandingan kebahasaan antara bahasa Bima dan bahasa Sabu.

Mengingat adanya keunikan kedua bahasa dan memulai adanya penggerusan kedua bahasa tersebut oleh populernya Bahasa Indonesia di daerah itu, dalam perdagangan, pemerintahan, dan pekerjaan. Begitu juga dengan adanaya penggunaan Bahasa Indonesia di sekolah maupun ditempat ibadah lainnya. Maka diperkirakan kedepan pengguanaan bahasa daerah tersebut terdesak oleh Bahasa Indonesia. Dengan demikian, sangatlah mungkin kedepan terjadi kepunahan kedua bahasa itu. Untuk menghindari kepunahan itu, maka pencatatan tentang keterkaitan kedua bahasa tersebut sangat perlu dan segera harus dilakukan. Itulah sebabnya dalam artikel ini ditulis tentang kekerabatan Ekolinguistik antara Bahasa Bima dan Bahasa Sabu untuk mengetahui sejauh mana kekerbatan kedua bahasa tersebut. Hasil dari studi ini merupakan sebuah catatan bagi generasi muda dari kedua penutur bahasa tersebut akan mengetahui jejak masa lampau dari leluhurya dan dari hasil studi ini akan diketahui sejauhmana keeratan kekeluargaan secatra Ekolinguistik dari kedua penutur tersebut.

\section{HASIL ANALISIS}

Berdasarkan analisis glos 200 Kosakata Daftar Swadesh ditemukan kosakata berkerabat dekat, antara bahasa Sabu dan Bahasa Bima. Secara keseluruhan ditemukan 56 glos yang kognat. Bila ditelusuri lebih jauh tanpak tampak etimon Proto Austronesia (PAN) wariskan dalam 2 bentuk, yang pertama etimon dengan tanpa perubahan phonologis maupun tanpa perubahan leksikal; yang kedua yaitu etimon dengan perubahan phonologis dan dengan perubahan leksikal. 


\section{Etimom PAN yang tidak Mengalami Perubahan}

Etimom PAN yang tidak mengalami perubahan phonologis dan leksikal pada kedua bahasa itu meliputi 3 etimon yang bermakna 'bapak', yaitu PAN *ama $\rightarrow$ Sabu ama, Bima ama; 'ibu', yaitu PAN *ina, Sabu ina, Bima ina; dan 'bunga', yaitu PAN *buna $\rightarrow$ Sabu buna, Bima buna.

\section{Etimom PAN yang Mengalami Perubahan}

Sedangkan etimom PAN yang diwariskan dengan perubahan phonologis berjumlah 53 glos, yaitu: pada kata yang bermakna 'orang', PAN *tau $\rightarrow$ Sabu dou, Bima dou; 'laki-laki' PAN *waNay $\rightarrow$ Sabu wamone, Bima mone; 'nama', PAN * naran $\rightarrow$ Sabu nara, Bima nara; 'kulit', PAN *qaNiC $\rightarrow$ Sabu kuri, Bima kalita; 'punggung', PAN *likuD $\rightarrow$ Sabu kodo, Bima kontu'; 'hati' PAN * Qatay $\rightarrow$ Sabu ade, Bima ade; 'Susu' PAN * Ra(CtT)as $\rightarrow$ Sabu huhu, Bima susu; darah, PAN * dayah $\rightarrow$ Sabu ra, Bima ra; 'leher', PAN * li:qeR $\rightarrow$ Sabu koko, Bima wo'o; 'mata', PAN *mata $\rightarrow$ Sabu mada, Bima mada; 'cacingalwo', PTSL *kulai $\rightarrow$ Sabu kelate, Bima koli; 'kutu', PAN * ańk'an $\rightarrow$ Sabu udu, Bima hudu; 'telur', PAN *toluR $\rightarrow$ Sabu dallu, Bima dolv; 'kayu', PAN * Pa(r)k'an $\rightarrow$ Sabu aju, Bima haju; 'rumput', PAN *dukut $\rightarrow$ Sabu ruju'u, Bima mpori; 'daun', PAN * Dáhwen $\rightarrow$ Sabu rauaju, Bima ro'o; 'akar', PAN * t'uńkal $\rightarrow$ Sabu amo, Bima amu; 'buah', PAN *buaq $\rightarrow$ Sabu wue, Bima wua; 'makan', PAN *ka?en $\rightarrow$ Sabu naa, Bima $\eta a h a ;$ 'rumah', PAN *rumaq $\rightarrow$ Sabu dmmu, Bima uma; 'jarum', PAN * d'aRum $\rightarrow$ Sabu jajau, Bima nda'u; 'tali', PAN *tali $\rightarrow$ Sabu dari, Bima ai; 'abu', PAN *aBuh $\rightarrow$ Sabu awu, Bima rawu; 'api', PAN *apuy $\rightarrow$ Sabu ai, Bima afi; 'asap', PAN *asu $\rightarrow$ Sabu habbu, Bima obu; 'pasir', PAN *kesik $\rightarrow$ Sabu wolahalae, Bima sarae; 'air', PAN *[ dd ] anum $\rightarrow$ Sabu ei, Bima woi; 'minyak/lemak', PAN *məńak $\rightarrow$ Sabu mañnii,

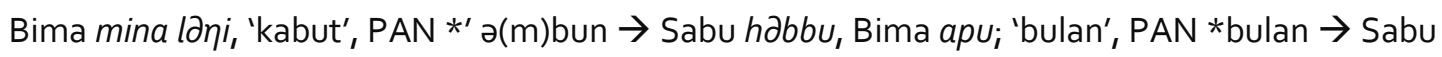
wdrru, Bima wura; 'mencium', PAN * ba'u' $\rightarrow$ Sabu hendddu, Bima nu; 'tertawa', PAN *tawa $\rightarrow$ Sabu mari, Bima hari; 'menangis', PAN * ta(m)ba $\rightarrow$ Sabu tani, Bima nani; 'menjahit', PAN * d'ahit $\rightarrow$ Sabujau, Bima nda'v; 'menikam', PAN *kam $\rightarrow$ Sabu petzbbu, Bima tuba; 'membunuh', PAN * bunùq $\rightarrow$ Sabu pemade, Bima hade; 'menggaruk', PAN *kuskus $\rightarrow$ Sabu (ta)kao, Bima kao;

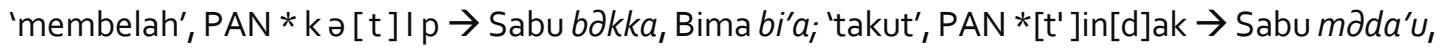
Bima dahu; 'mati', *matay $\rightarrow$ Sabu made, Bima made; 'hidup', PAN *quDip $\rightarrow$ Sabu muri, Bima mori; 'tajam', PAN * tad'əm $\rightarrow$ Sabu na'a, Bima $\eta a h a ;$ 'busuk', PAN *(bB)uRuk $\rightarrow$ Sabu wou, Bima wou; 'panas', PAN *dadáñ $\rightarrow$ Sabu pana, Bima pana; 'tipis', PAN *nipis $\rightarrow$ Sabu mani, Bima nipi; 'baru', PAN * baRu $\rightarrow$ Sabu wiu, Bima bou; 'hitung', PAN *(qS)I(n)tu $\eta \rightarrow$ Sabu reke, Bima reke; 'dua', PAN *duwa $\rightarrow$ Sabu due, Bima d'ua; 'tiga', *təlu' $\rightarrow$ Sabu tallu, Bima tolu; 'empat', PAN *ə(m)pat $\rightarrow$ Sabu dppa, Bima upa, 'hitam', PAN * I(n)təm $\rightarrow$ Sabu maddi, Bima me'e; 'tahun', PAN *taqun $\rightarrow$ Sabu tau, Bima tahun.

Bentuk glos yang mengalami perubahan fonem berupa penghilangan fonem di belakang kata, baik pada Bahasa Sabu maupun pada kata Bahasa Bima, yaitu kata yang bermakna 'nama' PAN 


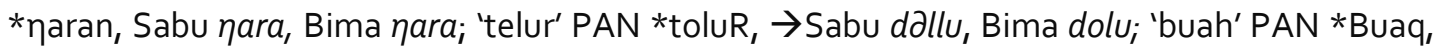
$\rightarrow$ Sabu wue, Bima wua; 'minyak' PAN *məńak $\rightarrow$ Sabu maññi, Bima mina; 'empat' PAN *ə(m)pat $\rightarrow$ Sabu дppa Bima upa. Penghilangan fonem di depan dan dibelakang kata, seperti pada kata yang bermakna 'rumah' PAN *Rumaq, Sabu dmmu, Bima uma; Penghilangan ditengah kata pada kata bermakna 'baru' PAN *bayu $\rightarrow$ yaitu Sabu wiu, Bima bou. Perubahan berupa monoptongisasi kata yang bermakna 'mati' PAN *matay $\rightarrow$ Sabu made, Bima made *apuy $\rightarrow$ Sabu $a-i_{\perp}$ Bima afi. Perubahan fonem didepan kata pada kata bermakna 'bulan' PAN *bulan $\rightarrow$ Sabu wdrru, Bima wura; 'batu' PAN *batu $\rightarrow$ Sabu wadu, Bima wadu; 'telur' PAN *toluR $\rightarrow$ Sabu dəllu, Bima dolu. Perubahan fonem pada bahasa Sabu dan penghilangan fonem pada bahasa Bima pada kata yang bermakna 'tali' PAN *tali $\rightarrow$ Sabu dari, Bima ai; 'tahun' PAN *taqun $\rightarrow$ Sabu tau Bima tahun. Dengan perubahan ditengah pada kata dengan makna 'mata' PAN * mata, Sabu mada, Bima mada, 'tiga' PAN *təlu $\rightarrow$ Sabu tzllu Bima tolu. Penambahan pada depan kata dan penghilangan pada belakang pada kata yang bermakna 'kabut', PAN * ə(m)bun $\rightarrow$ Sabu habbu, Bima apu; Seanjutnya ditemukan pula inovasi leksikon pada kata yang be rmakna 'kutu' PAN *an̉k'an, Sabu udu, Bima hudu; 'akar' PAN *t'uńkal $\rightarrow$ Sabu amo, Bima amu; 'kulit' PAN *qaNiC $\rightarrow$ Sabu kuri, Bima kalita; 'darah' PAN *dayah $\rightarrow$ Sabu ra, Bima ra'a; 'hidup' PAN *quDip $\rightarrow$ Sabu muri, Bima mori; 'busuk' PAN *(bB)uRuk $\rightarrow$ Sabu wou, Bima wou;'panas' PAN *dadáñ $\rightarrow$ Sabu pana, Bima pana; 'hitung' *(qS)I(n)tu $\eta \rightarrow$ Sabu reke, Bima reke; 'dua' PAN *duwa $\rightarrow$ Sabu due, Bima b'va

\section{Kekerabatan Secara Ekolinguistik}

Dari 56 kata berkerabat tersebut di atas, tanpak 28 di antaranya berkerabat secara ekolinguistik yaitu: kosakata yang bermakna cacing, kutu, dan telur (yang tergolong binatang dan satwa); kayu, daun, akar, bunga, dan buah (yang tergolong tumbuhan dan tanaman); jarum, tali, abu, api, air, minyak, kabut, bulan, asap, batu, pasir, dan air (tergolong benda dan lingkungan alam); tipis, baru, takut, mati, hidup, tajam busuk, dan panas (tergolong kategori sifat dan keadaan)

Penelitian lapangan menunjukkan pula bahwa di jaman dahulu pola hidup penutur kedua bahasa itu dulunya berpindah-pindah dan berpandangan bahwa semuanya harus didasarkan pada keselarasan dengan kepercayaan suku, atau atas pandangan bahwa segala sesuatu adalah merupakan pemberian Tuhan Yang Maha Kuasa sehingga segalanya harus dilakukan dalam suasana yang religi dalam kehidupan. Keseharian mereka selalu diawali dengan ritual-ritual dengan maksud memohon bimbingan, petunjuk, berkat serta penjagaan leluhur.

\section{KESIMPULAN}

Bahasa Sabu dan Bahasa Bima merupakan bahasa yang berbeda namun sama-sama memiliki kesamaan dan kemiripan fonetik dan keduanya sebagai keturunan PAN. Kemiripan bentuk itu 
dapat dijumpai pada 56 kosakata dari 200 kosakata Swadesh. Pantulan PAN pada kedua bahasa itu ada yang berbentuk tetap (retensi) atau mengalami perubahan fonem, penghilangan, penambahan fonem, atau keduanya, atau substitusi fonem. Selanjutnya, dari 56 kosakata itu ditemukan 28 kata berkaitan erat dengan lingkungan hidup Suku Bima dan Sabu. Kosakata itu meliputi kosakata yang bermakna cacing, kutu, dan telur (yang tergolong binatang dan satwa); kayu, daun, akar, bunga, dan buah (yang tergolong tumbuhan dan tanaman); jarum, tali, abu, api, air, minyak, kabut, bulan, asap, batu, pasir, dan air (tergolong benda dan lingkungan alam); tipis, baru, takut, mati, hidup, tajam busuk, dan panas (tergolong kategori sifat dan keadaan)

Dengan demikian, kekerabatan kedua bahasa itu tidak nampak hanya pada kekerabatan dekat secara kuantitatif saja, namun juga memiliki kedekatan kekerabatan dekat secara ekolinguistik namun juga memiliki kekerabatan yang disebabkan oleh peristiwa politis dan kawin-mawin pada masa-masa kerajaan Sabu-Bima-Makasar di jaman dulu.

\section{DAFTAR PUSTAKA}

Alwi, Hasan, dkk. 2003. Kamus Besar Bahasa Indonesia. Jakarta: Balai Pustaka.

Bire, Josua. 2013. Sabu Raijua of Indonesian Language Compounds. Open Science Repository Language and Linguistics.

Budasi, I Gede. 2007. Kekerabatan Bahasa-Bahasa Sumba Setudi Linguistik Histories Komparartif. Disertasi. Universitas Gajah Mada.

Budasi, I Gede. 2014. Status Kekerabatan Bahasa Sawu diantara Bahasa Daerah di NTT: Analisis Kuantitatif dan Kualitatif: Penelitian Dana DIPA Undiksha 